\title{
Modalities of Prescription of Regular Physical Activity by Cardiologists in the Management of Hypertensive Patients at the Institute of Cardiology of Abidjan
}

\author{
Koffi Djinguin1,2,3, Manou Koffi Benjamin1, Angoran Ines1,2, Ekou Arnaud1,2, Tanoh Micesse1,2, \\ Kramoh Euloge ${ }^{1,2}$
}

\author{
${ }^{1}$ Felix Houphouët Boigny University of Cocody, Abidjan, Côte d'Ivoire \\ ${ }^{2}$ Institute of Cardiology of Abidjan, Abidjan, Côte d'Ivoire \\ ${ }^{3}$ National Police Hospital, Abidjan, Côte d'Ivoire \\ Email: koffidjinguin@yahoo.fr
}

How to cite this paper: Djinguin, $\mathrm{K}$. Benjamin, M.K., Ines, A., Arnaud, E., Micesse, T. and Euloge, K. (2021) Modalities of Prescription of Regular Physical Activity by Cardiologists in the Management of Hypertensive Patients at the Institute of Cardiology of Abidjan. World Journal of Cardiovascular Diseases, 11, 445-457. https://doi.org/10.4236/wicd.2021.119042

Received: April 20, 2021

Accepted: September 20, 2021

Published: September 23, 202

Copyright $\odot 2021$ by author(s) and Scientific Research Publishing Inc. This work is licensed under the Creative Commons Attribution International License (CC BY 4.0)

http://creativecommons.org/licenses/by/4.0/ (c) (i) Open Access

\begin{abstract}
Introduction-Objective: The clinical management of hypertension is well codified. It is based on drug and non-drug therapies, including regular physical activity. The aim was to evaluate the knowledge of physicians on the importance of regular physical activity (RPA) in the care of hypertensive patients at the Institute of Cardiology of Abidjan (ICA). Material and Methods: That was a prospective and descriptive study carried out from July 20, 2019 to September 7, 2019 at the Outpatient Department of the ICA. Our study population consisted of 32 physicians from the Outpatient Department of the ICA. To achieve our goal, we developed a questionnaire for the physicians, which included seventeen items related to the socio-occupational characteristics, to the level of knowledge of hypertension, to the attitudes and the practices in the management of hypertension, and to the factors limiting the accessibility to the practice of a physical activity. Results: The majority of the health professionals in our study were men (62.50\%). Among 32 physicians, $56.25 \%$ were cardiologists and $75 \%$ had a seniority in position of 1 to 4 years. $81.25 \%$ of the physicians responded that the hypertensive patients could not only benefit from non-drug means. The suggestion of a complementary physical activity (jogging and brisk walking) to the hypertension treatment was found 137.5 times. Jogging and brisk walking were the main types of physical activity which were suggested to patients. All the physicians responded 3 times per week when they were asked about the frequency of activities proposed for the clinical management of patients with hypertension. Regarding the medical prescription on the type, frequency, and duration of
\end{abstract}


RPA to patients, there was some discrepancy, although the majority of healthcare professionals recommended brisk walking and jogging. Their responses for a 60 -minute physical activity were prevalent in $37.5 \%$ of cases. Regular physical activity ranked third in the management of the hypertensive patients. Nevertheless, all respondents proposed drug treatment associated with hygienic-dietary measures. $93.75 \%$ of health workers initially considered the physical condition of patients before they prepared them for the physical activity. The respondents regularly regarded the physical condition of the patient to evaluate the practice or not of an RPA at a frequency of 24 times in $57.89 \%$ of the cases. $93.75 \%$ of them confirmed that there was a positive relationship between the practice of the RPA and the improvement of the patient's clinical state. Conclusion: The knowledge of physical activity and its benefits on the organism remains a problem for its application even though the health professionals know its positive impact on the prevention and the treatment of hypertension.

\section{Keywords}

Knowledge, Physician, Regular Physical Activity, Hypertensive Patient, Institute of Cardiology of Abidjan

\section{Introduction}

The arterial hypertension $(\mathrm{AH})$ is a frequent disease that causes considerable cardiovascular complications [1]. Among the risk factors, there are the sedentary lifestyle and the passivity of individuals which are increasingly accentuated by the $\mathrm{AH}$. As the arterial hypertension expands on the world and does not spare any social stratum with its dramatic complications, the medical care remains one of the challenges to reduce it. The treatment of the AH is well codified [2]. The treatment of the $\mathrm{AH}$ is based on drug and non-drug means, including the medication, the healthier diet, and the regular physical activity (RPA). Indeed, the World Health Organization and all the scholar societies of cardiology [3] recommend physical activity as the first-line treatment for the hypertensive patients in combination with the dietary therapy. Physical activities reduce blood (BP) pressure by 5 to $7 \mathrm{mmHg}$ in hypertension. This drop in BP is independent of the reduction in weight and fat mass. The mechanisms behind this drop are multiple, interact with each other and vary from person to person. There is better adapted cardiac output, a decrease in peripheral arterial resistance of multiple origins with an improvement in endothelial vasodilation and a decrease in constriction of vessels effects of sympathetic tone and the renin-angiotensin-aldosterone system. Reduction of left ventricular hypertrophy (independent risk factor for cardiovascular disease) secondary to hypertension obtained from the PA is comparable to that obtained by diuretic treatment [3].

Moreover, the first-line therapy is inexpensive with a very few side effects [4]. The implementation of these recommendations, explains the low prevalence of 
the $\mathrm{AH}$ within athletes in the literature [3] [5]. However, the prevalence of hypertensive patients practicing RPA more than once a week is unknown in Africa, particularly in Côte d'Ivoire. Elsewhere, in Kuwait, Alsairafi et al. indicated in their paper that about $80 \%$ of patients reported that they received advice from their doctor to practice physical activity. But the proportion of patients practicing any kind of physical activity is only 34.5\% [6]. Furthermore, the other methods of the arterial hypertension care have been investigated in several studies in Africa [7] [8] [9]. To our knowledge, RPA is not known in sub-Saharan Africa. Hereby, the aim of this study was to evaluate the knowledge of physicians on the role of regular physical activity in the management of hypertensive patients at the Institute of Cardiology of Abidjan (ICA).

\section{Material and Methods}

That was a prospective and descriptive study done at the Outpatient Department of the ICA. It was conducted from July 20, 2019 to September 7, 2019 (48 days). Our study population consisted of the healthcare professionals (physicians) in the Outpatient Department of the ICA. The list of the physicians, present at the time of the survey, was made for the healthcare personnel. Practicing cardiologists of the ICA were included in our study. The physicians who were absent or unavailable during our survey, the nurses, and the assistant nurses were not included in this study.

To achieve our goal, a questionnaire, addressed to the physicians, was developed. This questionnaire contained items relating to the socio-professional characteristics, to the level of knowledge about the hypertension, to the attitudes and the practices of the management of the hypertension, and to factors affecting the patient's access to physical activity. We went to the consultation service with our instrument to avoid any possible biases that could come from the respondents.

\section{Statistical Analysis}

The data collected on a survey sheet will be entered into the EPI DATA software and analyzed on SPSS version 22 on a PC computer. Quantitative variables will be expressed as mean \pm standard deviation and qualitative variables as proportions.

\section{Results}

We arbitrarily selected 32 subjects for this pilot study.

\subsection{Socio-Professional Characteristics of Healthcare Personnel}

\section{Sex and age}

The majority of the physicians in our study were men (62.50\%) (Figure 1).

\section{Professional qualification}

In our study, $56.25 \%$ of the physicians were specialized in cardiology (Figure 2). 


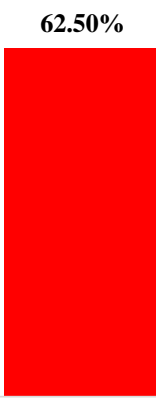

Male

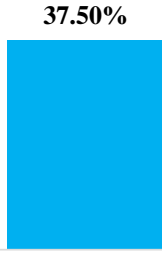

Female

Figure 1. Distribution of the physicians by gender $(n=32)$.

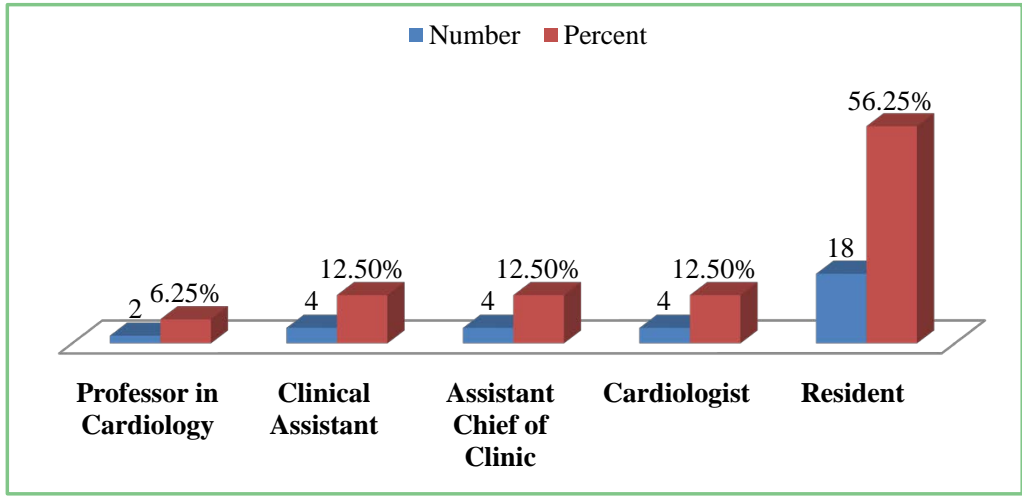

Figure 2. Distribution of physicians by title $(n=32)$.

\section{Seniority in the position}

All almost of the physicians (75\%) had a seniority of 1 to 4 years (Table 1 ).

\subsection{Knowledge and Attitudes of Physicians on the Management of Hypertension}

All the physicians answered that the hypertensive patients could not be only treated by drugs while $81.25 \%$ of them revealed that the hypertension cannot be uniquely controlled by non-drug means, such as hygienic-dietary measures and regular physical activity.

\subsection{Knowledge about the Relevance of Physical Activity in Patient Management}

\section{Healthcare professionals' response by type of proposed activity}

We had 137.5 times the proposition of jogging and brisk walking as physical activities for the care of hypertension (Figure 3).

\section{Healthcare professionals' response by frequency of proposed activities}

All healthcare professionals suggested a frequency of 3 activities per week for hypertensive patients.

\section{Responses related to the duration of physical activity}

The physical activity of 60 minutes was more commonly reported by $37.5 \%$ of the respondents (Table 2). 
Responses of healthcare professionals to highly recommended items of hypertension management

The regular physical activity was frequently recommended, followed by drug therapy (Figure 4).

Table 1. Distribution of the physicians by seniority in position $(n=32)$.

\begin{tabular}{ccc}
\hline Seniority at the department & Number & Percentage (\%) \\
\hline $1-4$ years & 24 & 75.00 \\
$5-9$ years & 6 & 18.75 \\
$10-14$ years & 2 & 6.25 \\
Total & 32 & 100 \\
\hline
\end{tabular}

Table 2. Distribution of responses according to duration of physical activity.

\begin{tabular}{ccc}
\hline Activity duration & Number & Percentage (\%) \\
\hline 30 minutes & 10 & 31.25 \\
45 minutes & 10 & 31.25 \\
60 minutes & 12 & 37.50 \\
Total & 32 & 100
\end{tabular}

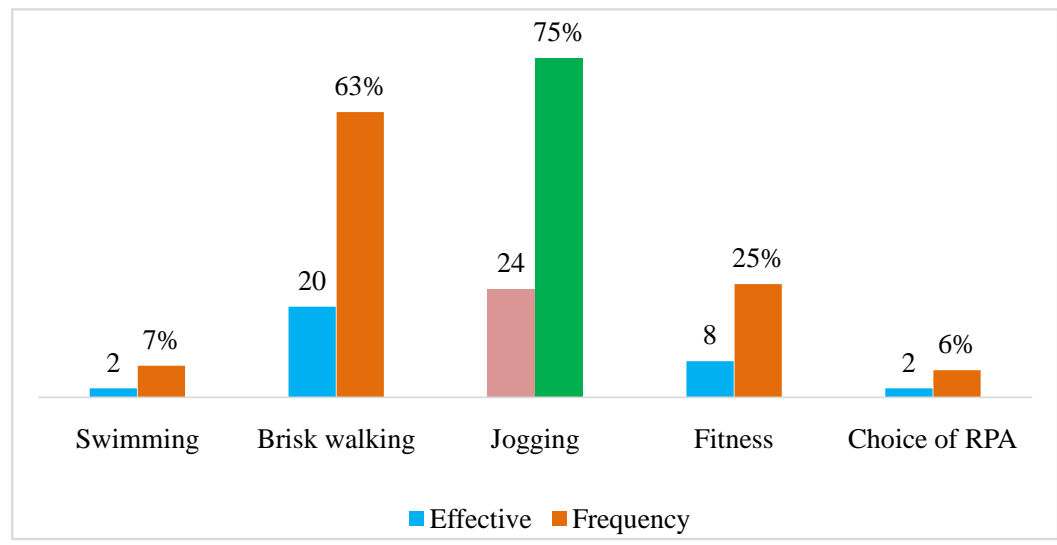

Figure 3. Distribution of the physicians' response by type of proposed activity (n $=32$ ).

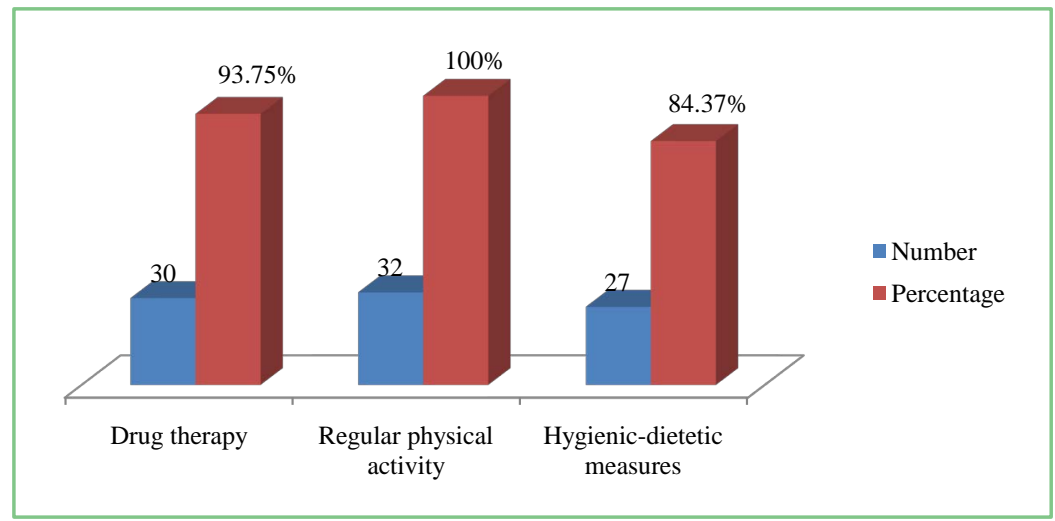

Figure 4. Distribution of the physicians' responses by items of hypertension management $(n=32)$. 
Knowledge of the combined means in the management of hypertension

$68.75 \%$ of the healthcare professionals confirmed that there was a sufficient combination of 2 treatment methods to implement for efficient care of hypertensive patients.

$>$ Evaluation of possible combinations for the management of hypertension

All physicians (100\%) proposed drug therapy in combination with hygienic-dietary measures. This would explain why all physicians in our study considered physical activity as a second-line treatment (Table 3 ).

$>$ Healthcare professionals' responses on the questioning items of patients during consultations

The health professionals were concerned about the proper follow-up of the measures prescribed to the patients (Figure 5).

Responses regarding the physiological and hemodynamic parameters necessary to propose physical activity to patients

Among 32 physicians, $93.75 \%$ considered the physical condition of the patients before proposing the physical activity (Table 4).

Frequency of responses related to the type of physical activity recommended to patients

Jogging and brisk walking were recommended 137.5 times (Figure 6).

Evaluation parameters in the proposition of RPA to patients

Our study showed that $57.89 \%$ of the physicians regularly regarded the patient's physical condition to evaluate the practice or not of an RPA at a frequency of 24 times (Table 5).

Table 3. Distribution of possible combinations for the management of hypertension $(\mathrm{n}=$ 32).

\begin{tabular}{ccc}
\hline Possible combinations & Number & Percentage (\%) \\
\hline Drug treatment and HDM & 32 & 100 \\
Drug treatment and practice of RPA & 18 & 81.82 \\
Practice of RPA and HDM & 6 & 27.27 \\
\hline
\end{tabular}

HDM: hygienic-dietary measures; RPA: Regular physical activity.

Table 4. The distribution of responses related to physiological and hemodynamic parameters of patients when proposing their physical activity.

\begin{tabular}{ccc}
\hline Parameters & Number & Percentage (\%) \\
\hline Physical condition of patient & 30 & 93.75 \\
Patient's willingness to practice physical activity & 8 & 25.00 \\
Normal or abnormal ECG & 6 & 18.75 \\
$\begin{array}{c}\text { Complementary examinations } \\
\text { (Holter blood pressure, stress test, blood test) }\end{array}$ & 8 & 25.00 \\
Others & 2 & 6.25
\end{tabular}


Table 5. Frequency of responses for assessment parameters in proposing RPA to patients.

\begin{tabular}{ccc}
\hline Parameters & Number of cases & Percentage (\%) \\
\hline Patient's statement & $\mathbf{2 2}$ & $\mathbf{5 7 . 8 9}$ \\
Curve of weight & 8 & 21.05 \\
Numbers of PA & 16 & 42.11 \\
Values of biological tests & 4 & 10.53 \\
Patient's physical condition & 24 & 63.16
\end{tabular}

PA: Physical activity.

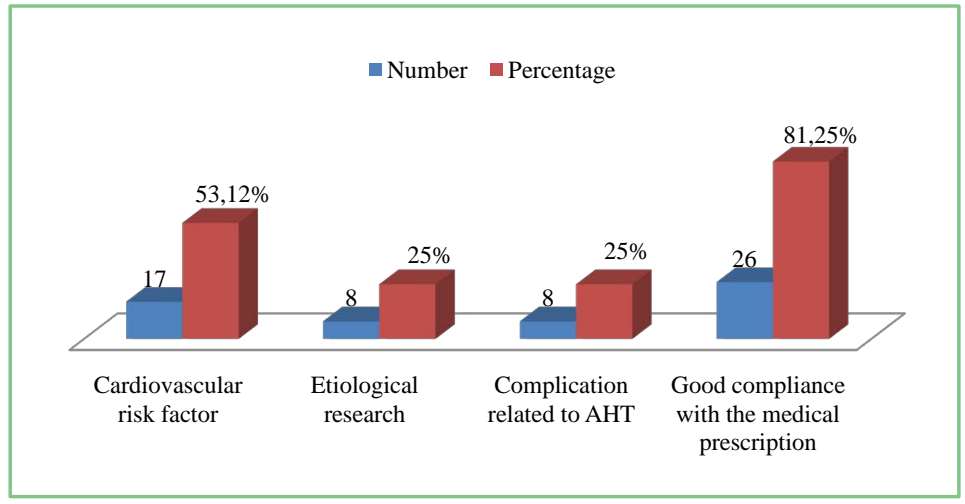

Figure 5. Distribution of physicians' responses to patient questioning items during consultations $(\mathrm{n}=32)$.

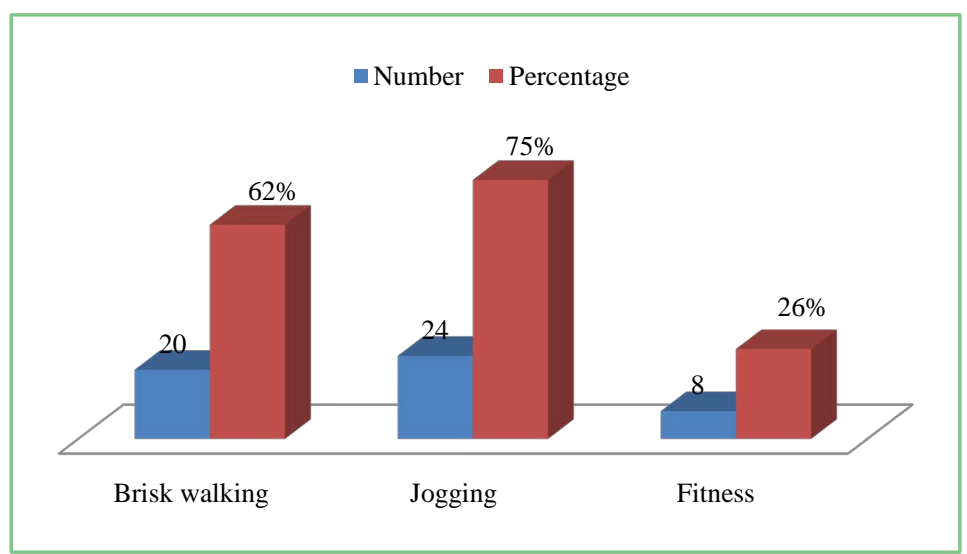

Figure 6. Frequency of responses related to the type of physical activity recommended for patients $(n=32)$.

Assessment of knowledge on the relationship between PRA and clinical condition

93.75\% of the healthcare professionals reported that the PRA was associated with the improvement of the patient's clinical condition.

Evaluation of the judgement criteria related to the improvement items of the clinical condition by the PRA

Several factors were considered in the improvement items of clinical condition, although $62.50 \%$ of the respondents observed that weight loss was correlated to the regular physical activity (Figure 7). 


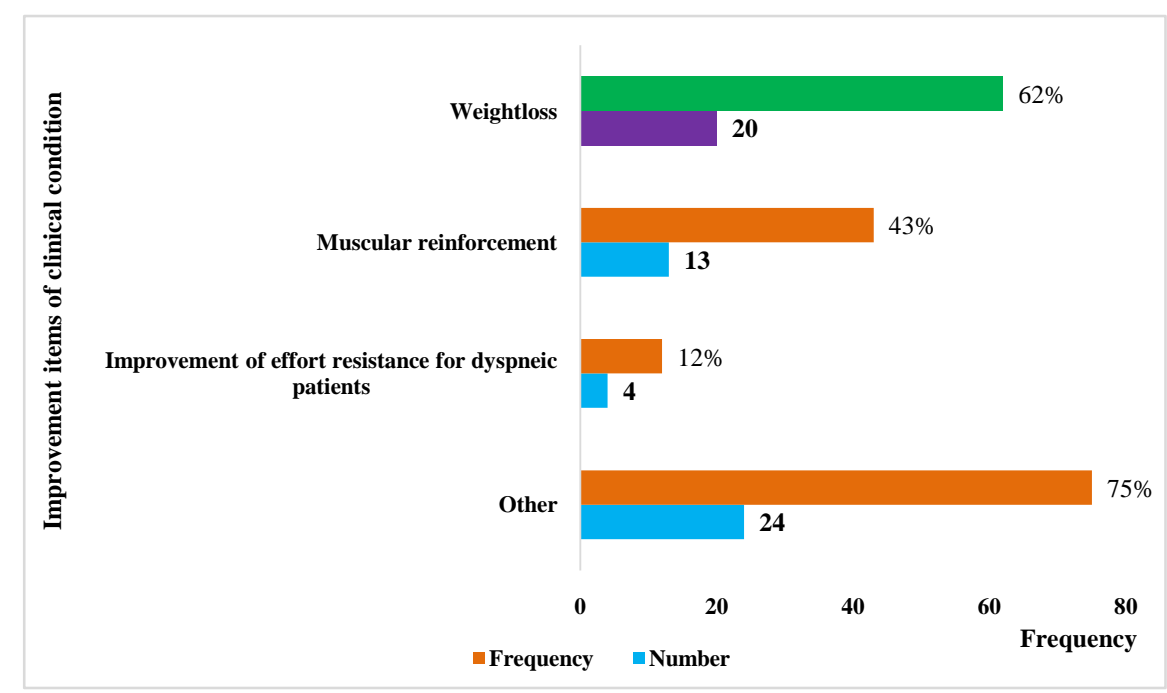

Figure 7. Frequency of improvement items of clinical condition $(n=32)$.

All physicians highlighted the benefits of RPA for the quality of life of hypertensive patients. These advantages were muscular reinforcement and improvement of the functional stage of the NYHA. The "Others" chapter refers to the improvement of other factors, including blood pressure level, heart rate, arrhythmias, LDL cholesterol uptake and the HDL cholesterol increase.

\section{Discussion}

\section{Limits of our study}

The difficulties encountered in our study resided in the constitution of our study population. Indeed, medical doctors were often not available to submit to questions. This explains the small size of the population. Nevertheless, this study retains all its value, because it is to our knowledge, the first on the evaluation of physical activities as an integral part of the management of hypertension.

\section{Discussion of the results}

In our study, the majority of the physicians were men (62.50\%) with an average age of between 20 and 40 years. They were relatively young with a seniority of 4 years. More than half (56.25\%) of our study population were cardiologists, who were admitted at the ICA for their cardiology residents. The academic authorities have well integrated the NICE guidelines on hypertension [9] which empower their students very early. Objectively, the NICE guidelines indicate that clinicians should check the diet and the exercise habits of the hypertensive patients since a healthy diet and a regular physical activity can reduce the blood pressure [10]. Regarding the knowledge of the management of hypertension, healthcare professionals have a good understanding of this disease and its management. Concerning the medical prescription on the type, the frequency, and the duration of PA for the patients with hypertension, there was some discrepancy although almost all physicians proposed brisk walking and jogging. According to the literature, the number of physicians recommending the physical 
activity as a non-drug treatment for the care of hypertensive patients is not clearly known, although it is likely to be low [11]. Several intervention schedules have been studied for the type of sport [12] [13]. However, there is no consensus on the minimum and the optimal levels of physical activity considered necessary for a therapeutic effect on blood pressure. These levels of PA are likely to vary from one individual to another. Low to moderate intensity of the aerobic endurance exercises (40\% - 70\% $\left.\mathrm{VO}_{2} \max \right)$ [14] appears to be highly effective in reducing significantly the blood pressure over the long-term practice. Longer exercise durations (30 - 45 minutes per session) seem to be more effective in reducing blood pressure than shorter sessions [15]. It is important to continue exercising regularly since its effect on blood pressure is lost after 10 weeks of recovery [16]. Our study showed that healthcare professionals consider the combination of drug treatment with PA as a second-line option. This could be explained by the fact that the practice of the physical activity, as a health care tool can be time consuming during a consultation. The physicians could not also understand the most appropriate and the safest exercise interventions for many patients [11]. In our study, $81.25 \%$ of physicians were concerned about the good compliance with the prescribed treatment. This implies a better follow-up of the patients with respect to their physiological and hemodynamic parameters in order to propose them a PA.

As for the evaluation of the practice of physical activity or not, it is usually based on the physical condition of the patient. Brooks and Ferro [11] recommend a number of steps along with the physical condition of each patient to the physicians for physical activity as an intervention for the management of hypertension. These steps are:

- the identification of the minimum level of physical activity required for health benefits;

- the determination of the patient's current level of physical activity;

- the determination of the patient's willingness to increase his physical activity levels;

- and the control of the participation.

\section{Conclusion}

The management of hypertension is a major problem for both physicians and patients. The diagnosis of hypertension is often late. All elements of the medical management of hypertension are not used to offer a better-quality care to patients, particularly the physical activity. Our study highlights that the knowledge of physical activity and of its benefits of the body remains a problem for its application although the physicians are aware of its relevant role in the prevention and the treatment of the hypertension. It is necessary to encourage the health professionals to prescribe and to raise awareness for the practice of physical activity within hypertensive patients for their well-being and their satisfactory life quality. 


\section{Conflicts of Interest}

The authors declare no conflicts of interest regarding the publication of this paper.

\section{References}

[1] World Health Organization (2011) Global Status Report on Non-Communicable Diseases 2010. World Health Organization, Geneva.

[2] Chobanian, A.V., Bakris, G.L., Black, H.R., et al. (2004) The Seventh Report of the Joint National Committee on Prevention, Detection, Evaluation, and Treatment of High Blood Pressure. National Heart, Lung, and Blood Institute, Bethesda.

[3] Girerd, X., Hanon, O., Pannier, B., Vaisse, B. and Mourad, J.J. (2013) Évolution dans l'usage des traitements antihypertenseurs en France entre 2002 et 2012: Enquêtes FLAHS. Annales de Cardiologie et d’ Angéiologie, 62, 210-214. https://doi.org/10.1016/j.ancard.2013.04.011

[4] Pescatello, L.S., Franklin, B.A., Fagard, R., Farquhar, W.B., Kelley, G.A. and Ray, C.A. (2004) American College of Sports Medicine Position Stand. Exercise and Hypertension. Medicine \& Science in Sports \& Exercise, 36, 533-553. https://doi.org/10.1249/01.MSS.0000115224.88514.3A

[5] Williams, P.T. (2009) Lower Prevalence of Hypertension, Hypercholesterolemia, and Diabetes in Marathoners. Medicine \& Science in Sports \& Exercise, 41, 523-529. https://doi.org/10.1249/MSS.0b013e31818c1752

[6] Alsairafi, M., Alshamali, K. and Al-Rashed, A. (2010) Effect of Physical Activity on Controlling Blood Pressure among Hypertensive Patients from Mishref Area of Kuwait. Electronic Journal of General Medicine, 7, 377-384. https://doi.org/10.29333/ejgm/82889

[7] Konin, C., Kramoh, E., Anzouan-Kacou, J.B., Essam N’Loo, A., Yayé, A., N’Djessan, J.J. and Adoh, M. (2012) Approche diagnostique et prise en charge de l'hypertension artérielle chez le personnel soignant du district d'Abidjan (Côte d'Ivoire). Revue d' Épidémiologie et de Santé Publique, 60, 41-46. https://doi.org/10.1016/j.respe.2011.07.006

[8] Adoubi, K.A., Nguetta, R., Yangni-Angate, K.H., Diby, K.F. and Adoh, A.M. (2006) Aspects épidémiologiques, cliniques et thérapeutiques de 1 'Hypertension artérielle à Bouake. Cahier Santé Publique, 5, 28-35.

[9] Lafay, V., Fourcade, L. and Bertrand, E. (2014) Prise en charge socioculturelle et médicale de l'hypertension artérielle en Afrique subsaharienne. Médecine et Santé Tropicales, 24, 283-288.

[10] National Clinical Guideline Centre (UK) (2011) Hypertension: The Clinical Management of Primary Hypertension in Adults. SAGE Publications, London.

[11] Brooks, J.H.M. and Ferro, A. (2012) The Physician's Role in Prescribing Physical Activity for the Prevention and Treatment of Essential Hypertension. JRSM Cardiovascular Disease, 1, 1-9. https://doi.org/10.1258\%2Fcvd.2012.012012

[12] Cornelissen, V.A. and Fagard, R.H. (2005) Effect of Resistance Training on Resting Blood Pressure: A Meta-Analysis of Randomized Controlled Trials. Journal of Hypertension, 23, 251-259. https://doi.org/10.1097/00004872-200502000-00003

[13] Cornelissen, V.A. and Fagard, R.H. (2005) Effects of Endurance Training on Blood Pressure, Blood Pressure-Regulating Mechanisms, and Cardiovascular Risk Factors. Hypertension, 46, 667-675. https://doi.org/10.1161/01.HYP.0000184225.05629.51 
[14] Fagard, R.H. and Cornelissen, V.A. (2007) Effect of Exercise on Blood Pressure Control in Hypertensive Patients. European Journal of Cardiovascular Prevention and Rehabilitation, 14, 12-17. https://doi.org/10.1097/HJR.0b013e3280128bbb

[15] Guidry, M.A., Blanchard, B.E., Thompson, P.D., Maresh, C.M., Seip, R.L., Taylor, A.L., et al. (2006) The Influence of Short and Long Duration on the Blood Pressure Response to an Acute Bout of Dynamic Exercise. American Heart Journal, 151, 1322.e5-1322.e12. https://doi.org/10.1016/j.ahj.2006.03.010

[16] Elley, R., Bagrie, E. and Arroll, B. (2006) Do Snacks of Exercise Lower Blood Pressure? A Randomized Crossover Trial. New Zealand Medical Journal, 119, Article No. U1996. 


\section{Survey Form}

Introduction

This investigation sheet is part of a research activity. It aims to assess the prescription of regular physical activity by cardiologists in the management of arterial hypertension at the Abidjan Cardiology Institute. The data collected will be kept confidential.

\section{Identity}

- Last name and first names

- Age (Years)

- Sex

\section{Professional data}

- What is your grade (circle): Professor Clinical Assistant Assistant Chief of Clinic Resident Cardiologist

- Number of years of medical practice (years):

3. Data on knowledge of regular physical exercise (RPA) and high blood pressure

- Is the treatment of hypertension only pharmacological? Yes No

- Do you think the APR has an interest in controlling BP? Yes No

- What other measures do you know in the management of hypertension: $\square$ limitation of salt consumption

$\square$ weight reduction

$\square$ practice of regular physical activity

$\square$ limit alcohol consumption to less than 3 glasses of wine or equivalent per day for men and 2 glasses of wine or equivalent per day for women

$\square$ diet rich in vegetables, fruits and low in saturated fat (fat of animal origin) $\square$ smoking cessation

- What type of sport do you offer to patients?

- What do you offer them?

- What is the minimum duration that you offer to patients?

\section{Supported for high blood pressure}

- According to the recommendations of learned societies, do you think that the above-listed hypertension management methods can be combined? Yes No

- If you have to offer an APR to a patient, what are the parameters to consider (Circle):

$\square$ Physical condition of patient

$\square$ Patient's willingness to practice physical activity

$\square$ Normal or abnormal ECG

$\square$ Complementary examinations (Holter blood pressure, stress test, blood test)

$\square$ Others (Lipid balance, Pulse oximetry ...)

5. Patient monitoring and evaluation

- Do you follow the prescription of non-pharmacological measures in the evaluation of hypertensive patients? Yes No 
- What are the terms discussed with patients in their follow-ups

- What is the impact of the APR on the state of health of your patients (Circle)?

$\square$ Improved physical condition

$\square$ Worsening of physical condition

$\square$ Improved blood pressure levels and heart rate

$\square$ Improved electrocardiographic data

$\square$ Improvement of lipid parameters

6. Physical data and APR

What are the physical parameters improved by APR? (Surround)

- Weightloss

- Muscle strengthening

- Ventilatory state

- Cardiac frequency

- Blood pressure levels 